\title{
Successful Therapy Using Pasireotide Long-acting Release for Cushing's Disease Merged with Biochemical Acromegaly
}

\author{
Kensaku Fukunaga ${ }^{1}$, Hitomi Imachi ${ }^{1}$, Seisuke Sato ${ }^{1}$, Toshihiro Kobayashi ${ }^{1}$, Yuki Yoshioka ${ }^{1}$, \\ Takanobu Saheki ${ }^{1}$, Natsuki Ban ${ }^{1}$, Kurumi Urushihara ${ }^{1}$, Jingya Lyu ${ }^{1}$, Tao Dong ${ }^{1}$, \\ Ryou Ishikawa ${ }^{2}$, Kyuichi Kadota ${ }^{2}$, Reiji Haba ${ }^{2}$, Naoko Inoshita ${ }^{3}$ and Koji Murao ${ }^{1}$
}

\begin{abstract}
:
It is quite rare that Cushing's disease shows acromegaly, and no pharmacotherapy has yet been discussed. A 21-year-old woman was diagnosed with Cushing's disease and underwent trans-sphenoidal surgery. Five years later, she was diagnosed with recurrent Cushing's disease and biochemical acromegaly because of elevated levels of serum growth hormone (GH), plasma insulin-like growth factor-1, plasma adrenocorticotropic hormone $(\mathrm{ACTH})$, and the 24-hour urinary excretion of free cortisol. After treatment initiation with pasireotide-long-acting release (LAR), both the ACTH and GH declined. Our case is the first to show the efficacy of pasireotide-LAR in controlling both Cushing's disease and acromegaly.
\end{abstract}

Key words: acromegaly, Cushing's disease, pasireotide long-acting release (LAR), somatostatin analog, plurihormonal pituitary adenoma

(Intern Med 60: 1047-1053, 2021)

(DOI: 10.2169/internalmedicine.4663-20)

\section{Introduction}

A functioning pituitary adenoma often secretes multiple anterior pituitary hormones; the most frequent hormonal combinations are prolactin (PRL) and growth hormone (GH) in the same cell lineage. Histologically, plurihormonal adenomas (PHAs) account for from 10-15\% of all functioning pituitary adenomas, but only a small number of PHAs secrete multiple hormones (1). In the normal pituitary gland, pluripotent progenitor cells can differentiate into 3 different cellular lineages that synthesize pro-opiomelanocortins (adrenocorticotropic hormone, ACTH); follicle-stimulating hormone (FSH) and luteinizing hormone (LH); and GH, PRL, and thyroid-stimulating hormone (TSH). Under such circumstance, it is quite rare that Cushing's disease shows acromegaly beyond the lineage. Regarding acromegaly, there is a pathological condition called "biochemical acromegaly" that has only been proven biochemically (2). Biochemical acromegaly does not exhibit the characteristic symptoms of acromegaly, so it is necessary to be careful not to miss the signs of this disease. In previous reports of cases of Cushing's disease associated with acromegaly, there were few reports that discuss the optimal medical therapies for this condition. We herein describe the case of a patient who demonstrated recurrent Cushing's disease merged with biochemical acromegaly treated with pasireotide long-acting release (LAR), a new second-generation somatostatin analog.

\section{Case Report}

A 21-year-old woman was diagnosed with Cushing's disease on close examination, beginning with hypokalemia 5 years ago. Her height and weight were $159 \mathrm{~cm}$ and $69 \mathrm{~kg}$ (body mass index: $27.3 \mathrm{~kg} / \mathrm{m}^{2}$ ), respectively. She had a blood pressure of $117 / 60 \mathrm{mmHg}$, and there was no abnormal glucose tolerance (HbA1c: $4.5 \%$, fasting blood glucose: $83 \mathrm{mg} / \mathrm{dL}$ ). She had acne on the torso, red skin streaks on

${ }^{1}$ Department of Endocrinology and Metabolism, Faculty of Medicine, Kagawa University, Japan, ${ }^{2}$ Department of Diagnostic Pathology, Faculty of Medicine, Kagawa University, Japan and ${ }^{3}$ Department of Pathology, Tokyo Metropolitan Geriatric Hospital and Institute of Gerontology, Japan

Received: February 13, 2020; Accepted: September 18, 2020; Advance Publication by J-STAGE: November 9, 2020

Correspondence to Dr. Kensaku Fukunaga, fukunaga@med.kagawa-u.ac.jp 
Table 1. Laboratory and Endocrine Data.

\begin{tabular}{|c|c|c|c|c|}
\hline & pre-operative & post-operative & 5 years later & normal range \\
\hline \multicolumn{5}{|l|}{ Chemistry } \\
\hline Sodium $(\mathrm{mEq} / \mathrm{L})$ & 143 & 143 & 143 & $135-146$ \\
\hline Chloride (mEq/L) & 105 & 107 & 106 & $96-110$ \\
\hline Potassium (mEq/L) & 3.4 & 4.0 & 4.4 & $3.5-4.6$ \\
\hline Total cholesterol (mg/dL) & 242 & 165 & 152 & $130-219$ \\
\hline LDL cholesterol (mg/dL) & 138 & 89 & 66 & $70-130$ \\
\hline HDL cholesterol (mg/dL) & 95 & 54 & 76 & $40-75$ \\
\hline Triglyceride (mg/dL) & 78 & 110 & 49 & $30-149$ \\
\hline Fasting plasma glucose $(\mathrm{mg} / \mathrm{dL})$ & 116 & 83 & 78 & 70-109 \\
\hline $\mathrm{HbA} 1 \mathrm{c}(\%)$ & 5.2 & 5.2 & 5.1 & $4.6-6.2$ \\
\hline \multicolumn{5}{|l|}{ Endocrine data } \\
\hline ACTH (pg/mL) & 106.1 & 5.0 & 63.4 & $7.2-63.3$ \\
\hline Cortisol $(\mu \mathrm{g} / \mathrm{dL})$ & 27.1 & 3.1 & 15.1 & $6.2-18.0$ \\
\hline $\mathrm{GH}(\mathrm{ng} / \mathrm{mL})$ & 0.30 & 0.21 & 4.90 & $0.66-3.68$ \\
\hline IGF-1 (ng/mL) & $354(192-611)$ & $279(192-611)$ & $461(168-459)$ & \\
\hline $\mathrm{LH}(\mathrm{mIU} / \mathrm{mL})$ & 0.4 & 1.8 & 2.4 & $0.5-15.0$ \\
\hline FSH (mIU/mL) & 5.7 & 7.5 & 6.2 & $1.3-6.2$ \\
\hline TSH $(\mu \mathrm{IU} / \mathrm{mL})$ & 0.51 & 0.64 & 0.91 & $0.35-3.73$ \\
\hline Free triiodothyronine $(\mathrm{pg} / \mathrm{mL})$ & 1.98 & 4.41 & 3.58 & $2.20-4.10$ \\
\hline Free thyroxine $(\mu \mathrm{g} / \mathrm{dL})$ & 0.94 & 1.06 & 1.32 & $0.88-1.81$ \\
\hline PRL (ng/mL) & 21.0 & 17.7 & 30.3 & $6.1-30.5$ \\
\hline Urinary free-cortisol $(\mu \mathrm{g} / \mathrm{d})$ & 509 & 40 & 406 & $11-80$ \\
\hline
\end{tabular}

LDL: low-density lipoprotein, HDL: high-density lipoprotein, ACTH: adrenocorticotropic hormone, GH: growth hormone, IGF: insulin-like growth factor, LH: luteinizing hormone, FSH: follicle-stimulating hormone, TSH: thyroid-stimulating hormone, PRL: prolactin

the lower abdomen, and thinning of the skin. She also had a moon face, central obesity, a buffalo hump, and menstrual irregularities. Endocrine examinations (Table 1) revealed that her plasma ACTH level (106.1 pg/mL) and 24-hour urinary excretion of free cortisol (509 $\mu \mathrm{g} /$ day) were both elevated, but serum levels of other pituitary hormones including basal serum $\mathrm{GH}(0.30 \mathrm{ng} / \mathrm{mL})$ and plasma insulin-like growth factor (IGF)-1 (354 ng/mL) were within normal ranges. Because magnetic resonance imaging (MRI) showed a lessenhanced mass in the left lobe of the pituitary gland (Fig. 1A), a trans-sphenoidal surgery was performed for a pituitary tumor (Fig. 1B). The adenoma cells showed diffuse immunopositivity for ACTH, and the proliferation rate (Ki67 labelling index) was $10 \%$ (Fig. 2A-C). The oral administration of hydrocortisone was started as postoperative replacement therapy. The dose was gradually reduced, and the treatment was discontinued 6 months later.

There was no sign of recurrence during the follow-up observation, and MRI showed no lesions with a suspected diagnosis of recurrence (Fig. 1C-D). However, 5 years after the operation, recurrence of Cushing's disease was suspected due to acne occurrence, hair loss, and menstrual irregularity. She was admitted to our hospital for scrutiny. On physical examination, her height was $160 \mathrm{~cm}$ and weight was $51 \mathrm{~kg}$ (body mass index: $19.9 \mathrm{~kg} / \mathrm{m}^{2}$ ). Her blood pressure was 113/ $51 \mathrm{mmHg}$. Acne was found on the torso, and red skin streaks were observed on the upper arm, popliteal fossa, and lower abdomen, but she did not present with a moon face, central obesity, or buffalo hump. She also did not have any signs of acromegalic appearances, such as macroglossia, deep nasolabial furrows, thick lips, and thickening of the hands and feet. With regard to the skin findings, there were no characteristic findings of acromegaly, such as skin thickening or excessive sweating, while thinning of the skin, characteristic of Cushing's disease, was observed. There was also no visual impairment. Endocrine examinations revealed that her plasma ACTH level $(63.4 \mathrm{pg} / \mathrm{mL})$ and 24-hour urinary excretion of free cortisol (406 $\mu \mathrm{g} /$ day) were elevated (Table 1). Endocrine examinations of the hypothalamicpituitary-adrenal (HPA) axis showed a lack of circadian rhythm of ACTH and cortisol; non-suppressibility to lowdose $(0.5 \mathrm{mg})$, but suppressibility to high-dose $(8 \mathrm{mg})$ dexamethasone (Table 2). The plasma ACTH level increased from 35.8 to $497.8 \mathrm{pg} / \mathrm{mL}$ after stimulation with corticotropin-releasing hormone (CRH) (Table 3). In addition, her serum GH (4.90 ng/mL) and plasma IGF-1 (461 $\mathrm{ng} / \mathrm{mL}$ ) levels were both elevated, and the serum GH level after a 75-g oral glucose load (Table 4) showed a paradoxical increase $(10.86 \mathrm{ng} / \mathrm{mL}$ at 30 minutes after glucose loading). Based on these results, she was diagnosed with recurrent Cushing's disease merged with biochemical acromegaly. MRI revealed no apparent residual pituitary tumor (Fig. 1E). We reviewed the pituitary adenoma specimens removed 5 years previously and confirmed that the adenoma cells 
A

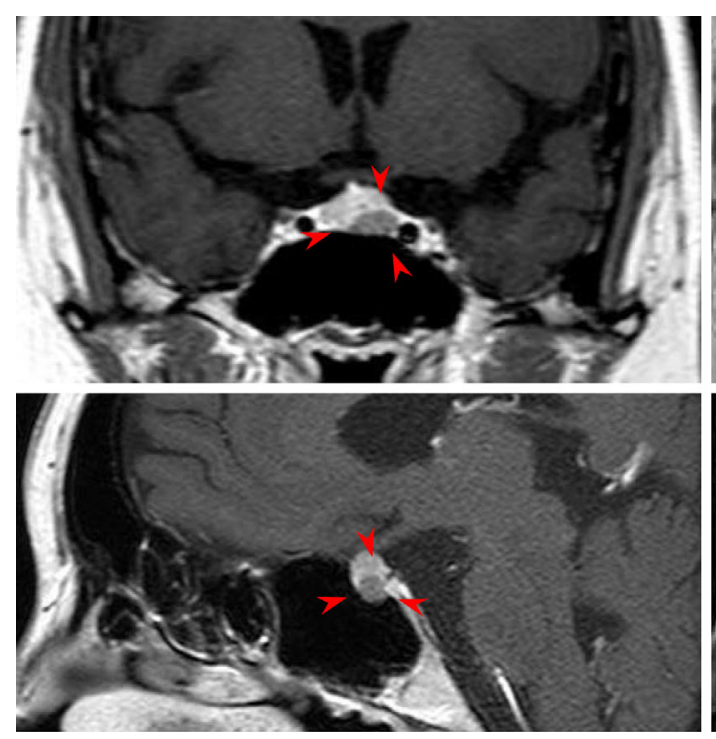

C

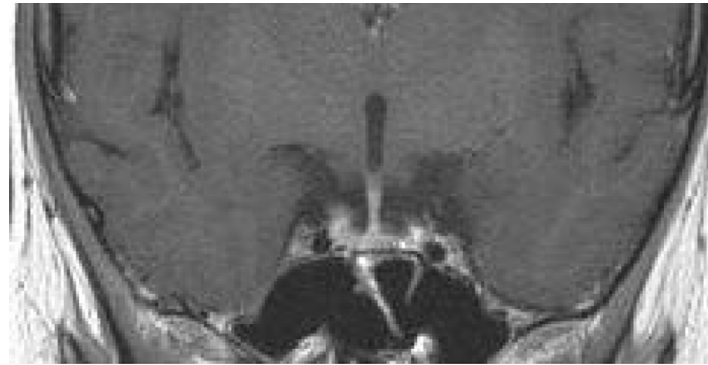

$\mathbf{E}$

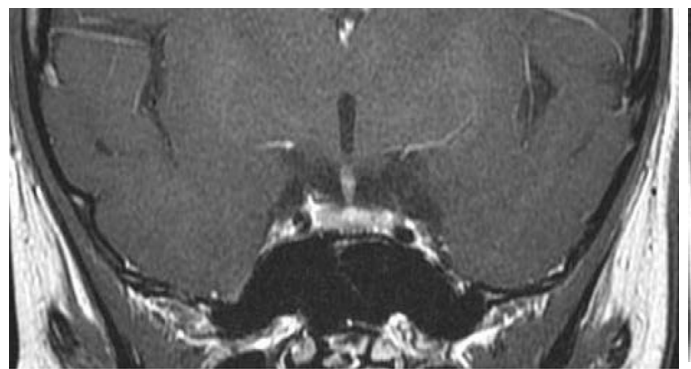

B

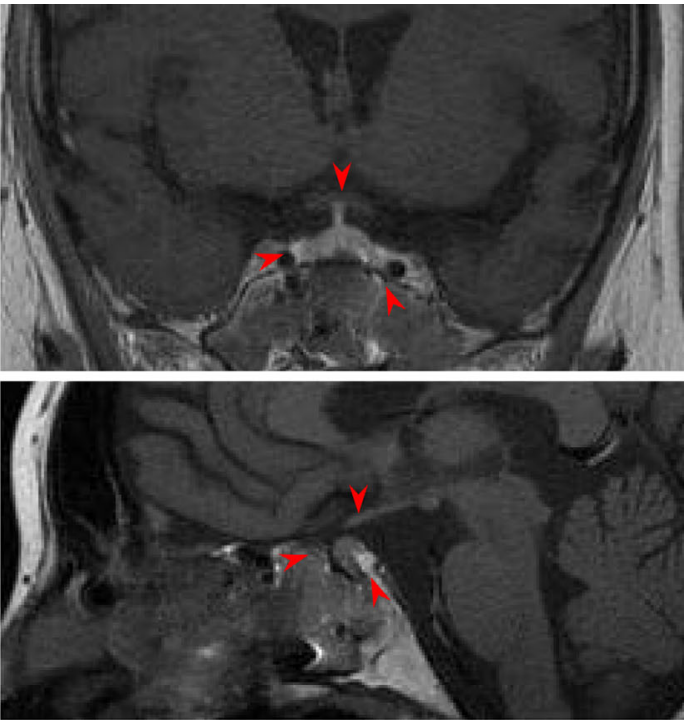

D

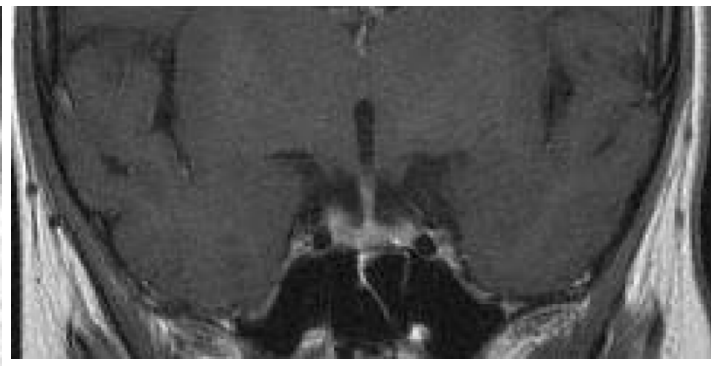

$\mathbf{F}$

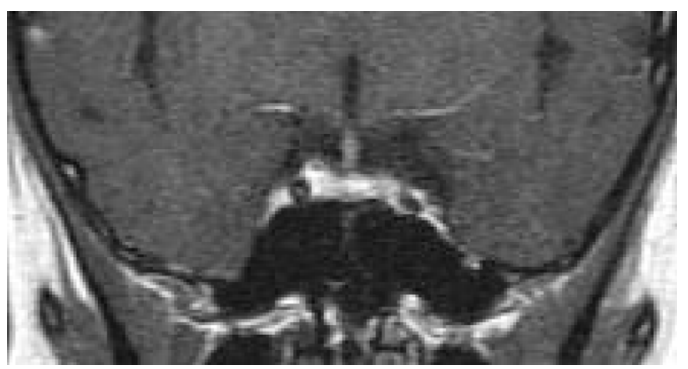

Figure 1. Magnetic resonance imaging (MRI) of the brain. (A) Pre-operative gadolinium-enhanced T1-weighted MRI showing the presence of a microadenoma. (B) MRI performed one week after surgery. Post-operative MRI showing the absence of any residual tumors. (C) MRI performed 6 months after surgery. (D) MRI performed one year after surgery. (E) MRI performed before pasireotide administration. (F) MRI performed 6 months after the start of pasireotide administration.

showed the immunopositivity for T-pit, but they did not show reactivity to GH and PIT-1 according to a histological analysis (Fig. 2D-F). In addition, we evaluated immunostaining of somatostatin receptor (SSTR). The scoring system proposed by Volante et al. (3) was applied to evaluate SSTR2 and SSTR5 immunostaining. This system is based on a 4-score grading system, which is based on the percentage of positive cells, with the following staining pattern and intensity: score 0, absence of immunoreactivity; score 1, pure cytoplasmic immunoreactivity, either focal or diffuse; score 2, membranous reactivity in less than $50 \%$ of tumor cells, irrespective of the presence of cytoplasmic staining; and score 3, circumferential membranous reactivity in more than $50 \%$ of tumor cells, irrespective of the presence of cytoplasmic staining. Using the Volante scoring system, SSTR5 was expressed in the adenoma cells (score 3), but SSTR2 was negative (score 1) (Fig. 2E, F). She initiated therapy with pasireotide-LAR (40 mg/month). Three weeks after the introduction of pasireotide-LAR, there was neither hyponatremia (serum sodium $139 \mathrm{mEq} / \mathrm{L}$ ), hypoglycemia (plasma glucose $105 \mathrm{mg} / \mathrm{dL}$ ), nor eosinophilia, but symptoms suggesting adrenal insufficiency, such as general malaise, were observed. Her plasma ACTH and serum cortisol levels were $17.2 \mathrm{pg} / \mathrm{mL}$ and $4.3 \mu \mathrm{g} / \mathrm{dL}$, respectively. There- 

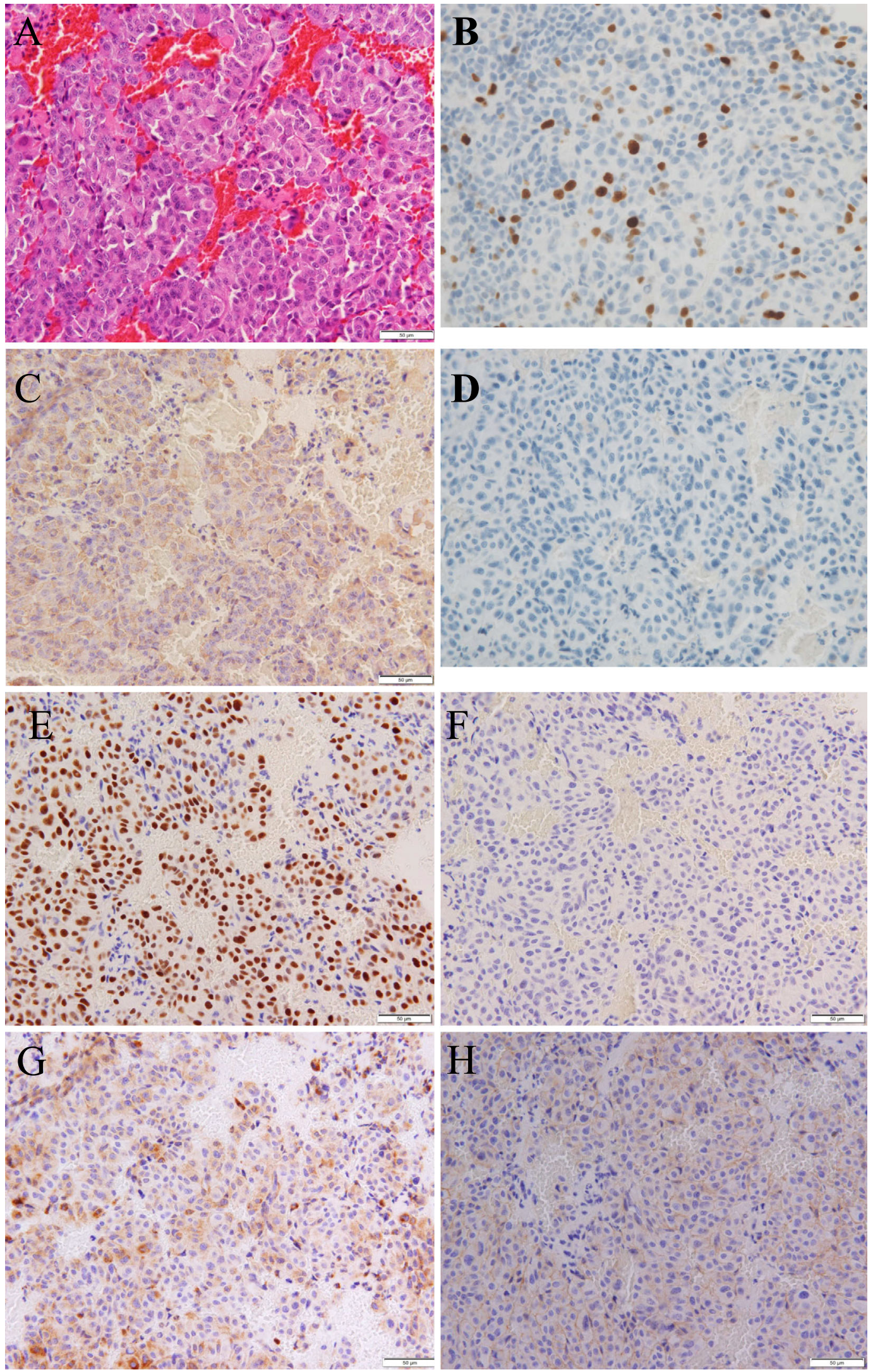

Figure 2. Histopathological and immunohistochemical study. Hematoxylin and Eosin staining for (A) magnification $\times 40$, and $(B)$ magnification $\times 40$. Tumor cells with a rounded nucleus grow solidly, and the proliferation rate (Ki67 labelling index) was $10 \%$. Immunostainings for (C) ACTH, and (D) GH (magnification $\times 40$ ). The adenoma cells showed diffuse immunopositivity for ACTH, and negative for GH. Immunostainings for (E) T-pit, (F) PIT-1, (G) SSTR2 and (H) SSTR5. Although the adenoma cells showed immunopositivity for T-pit and SSTR5, they were negative for PIT-1 and SSTR2. (magnification $\times 40)$ 
Table 2. Evaluation of ACTH-cortisol Hypersecretion.

\begin{tabular}{lccccc}
\hline & \multicolumn{2}{c}{ Diurnal rhythm } & & \multicolumn{2}{c}{ Dexamethasone suppression test } \\
\cline { 2 - 3 } \cline { 5 - 6 } & early morning & pre-sleep & & $0.5 \mathrm{mg}$ & $8 \mathrm{mg}$ \\
\hline ACTH $(\mathrm{pg} / \mathrm{mL})$ & 63.4 & 37.2 & & 33.8 & 6.3 \\
Cortisol $(\mu \mathrm{g} / \mathrm{dL})$ & 15.1 & 14.2 & & 14.9 & 2.2 \\
\hline
\end{tabular}

ACTH: adrenocorticotropic hormone

Table 3. CRH Stimulation Test Results.

\begin{tabular}{ccccc}
\hline Time $(\mathrm{min})$ & 0 & 30 & 60 & 90 \\
\hline ACTH $(\mathrm{pg} / \mathrm{mL})$ & 35.8 & 497.8 & 248.5 & 124.0 \\
Cortisol $(\mu \mathrm{g} / \mathrm{dL})$ & 17.0 & 30.4 & 36.6 & 38.3 \\
\hline
\end{tabular}

ACTH: adrenocorticotropic hormone

fore, the oral administration of hydrocortisone $(20 \mathrm{mg} /$ day $)$ was initiated in combination. Subsequently, the passage has remained unremarkable, and these treatments resulted in hormonal normalization, as shown in Fig 3. The acne that was identified before the treatment demonstrated any improvement. No side effects such as liver dysfunction were observed with the use of pasireotide. Although selfmonitoring of blood glucose was introduced and the blood glucose transition was confirmed, hyperglycemia was not observed and HbA1c did not worsen (approximately 5.3\%).

\section{Discussion}

Although several combinations of hormonally functioning double pituitary adenomas have been reported, the coexistence of acromegaly and pituitary Cushing's disease is quite rare. Most functioning pituitary adenomas reveal singlehormone production, but the employment of immunocytochemical analysis has revealed the existence of pituitary lesions with multiple hormonal expressions. In our case, we reviewed the pituitary adenoma specimens removed 5 years previously. Although immunostaining does not stain all resected tumors, we confirmed that the adenoma cells showed immunopositivity for ACTH, but they did not show reactivity to $\mathrm{GH}$ according to a histological analysis. From the above, we considered the possibility that GH hypersecretion had gradually developed after surgery, including the possibility that the number of $\mathrm{GH}$-positive cells, which were less expressed at the time of surgery, may have gradually increased. We also considered that ectopic GH or GHRHproducing tumors may have occurred after surgery, but we did not find any test results or imaging findings (for example, in the lungs or pancreas) that positively indicated the presence of ectopic tumors. Most causes of acromegaly are GH secreting pituitary adenomas, and acromegaly caused by a very small pituitary microadenoma that is not detected by pituitary MRI is rare (4). Therefore, pituitary MRI is the first step to localize the $\mathrm{GH}$ excess when biochemical diagnosis of acromegaly is confirmed, and adenomas that cause acromegaly are almost always visible on conventional MRI. However, there are several reports of patients with ac-
Table 4. The Results of $75 \mathrm{gOGTT}$.

\begin{tabular}{lcc}
\hline & $\mathrm{GH}(\mathrm{ng} / \mathrm{mL})$ & $\mathrm{BG}(\mathrm{mg} / \mathrm{dL})$ \\
\hline $0 \mathrm{~min}$ & 1.50 & 87 \\
$30 \mathrm{~min}$ & 10.86 & 123 \\
$60 \mathrm{~min}$ & 7.53 & 164 \\
$90 \mathrm{~min}$ & 2.04 & 140 \\
$120 \mathrm{~min}$ & 1.20 & 152 \\
\hline
\end{tabular}

romegaly pituitary adenomas could not be detected by MRI imaging $(5,6)$. In our case, although no new pituitary tumor was found in the follow-up of MRI images for 5 years, we diagnosed her with acromegaly based on the biochemical assessment including the serum GH level, age- and gendermatched serum IGF-1 level, and the result of $75 \mathrm{~g}$ oral glucose tolerance test (OGTT). Schneider et al. reported a high prevalence of undiagnosed acromegaly in primary care. Among them, they suggested that there are "biochemical acromegaly" patients whose acromegaly has been proved by just only biochemically (2). Some patients with biochemical evidence of acromegaly developed no clear-cut symptoms of acromegaly. Based on these results, there was no hypersecretion of GH from the pituitary adenoma at the time of surgery, suggesting that acromegaly might have developed during the patient's 5-year follow-up.

Clinically, PHAs are rare tumors that exhibit cellular immunoreactivity for more than one pituitary hormone (1). Functioning pituitary adenomas, the most frequent type, exhibit clinical syndromes due to pituitary hormonal oversecretion. A common feature of GH-ACTH PHA is the clinical dominance related to $\mathrm{GH}$ overproduction $(1,7)$. A recent review described 12 cases of ACTH-GH PHA in a dedicated review; upon analyzing specific pathognomonic clinical features, they found that 8 of the 12 patients $(66 \%)$ had only clinically manifested acromegaly without clinical evidence of Cushing's disease (1). This phenomenon has been defined as subclinical Cushing's disease, which may be caused by an insufficiency of autonomic ACTH production or by biologically inactive ACTH (7). In our case, the patient has the excessive secretion of both ACTH and GH with significant clinical manifestations of Cushing's disease, but not acromegaly. This is an unusual case that may involve the active secretion of ACTH together with GH. It may be difficult to suspect the presence of PHA based only on clinical, biochemical, or imaging features. Roca et al. reported that pituitary tumors in PHA patients show microadenomas in 6 of 20 patients; however, only 4 of 20 PHA patients presented with clinical signs of both acromegaly and Cushing's 

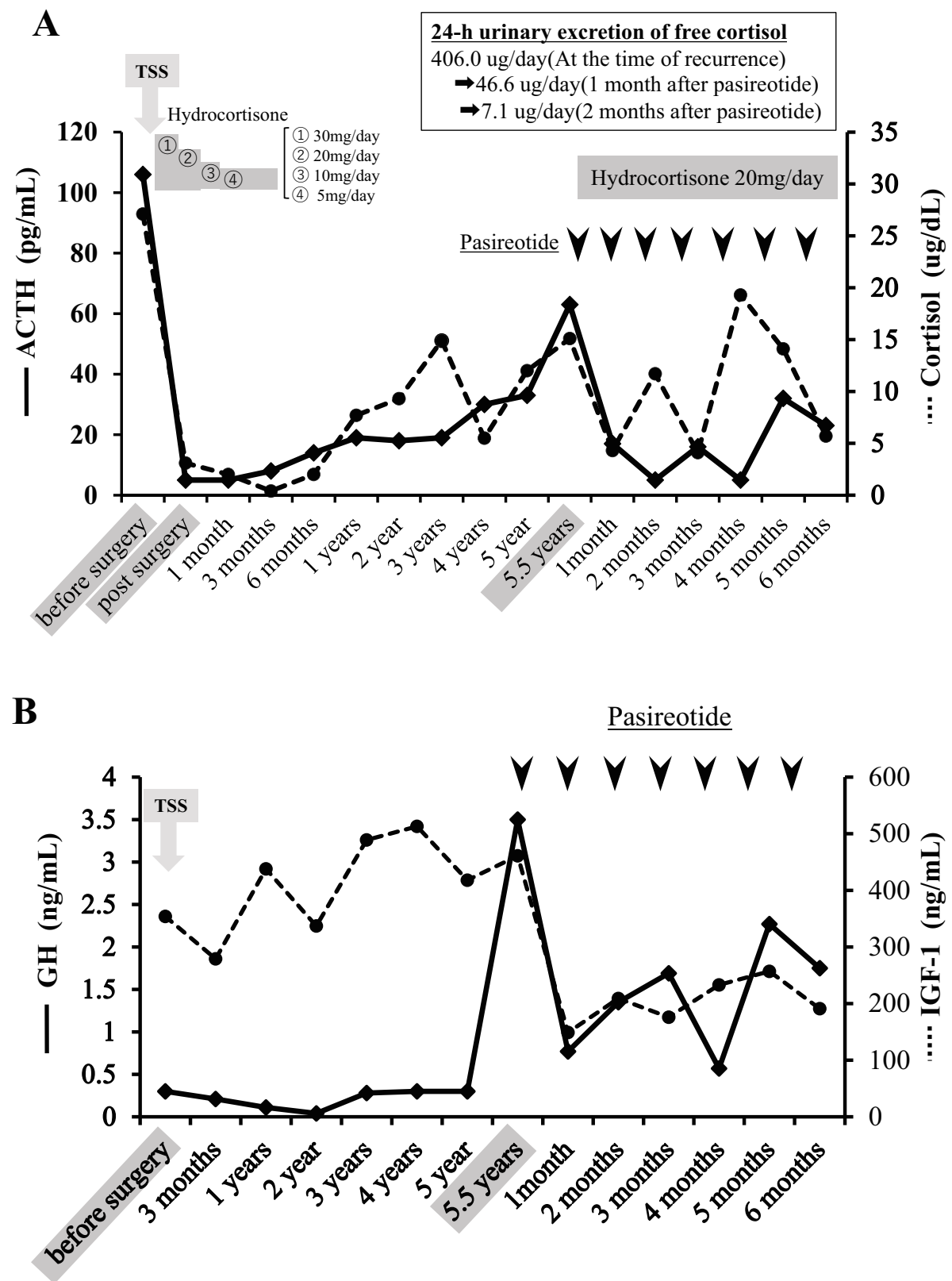

Figure 3. Clinical course of the patient. (A) The solid line indicates the plasma adrenocorticotropic hormone (ACTH) level, and the broken line indicates the serum cortisol level. TSS: transsphenoidal surgery. (B) The solid line indicates serum growth hormone (GH) level, and the broken line indicates the plasma insulin-like growth factor-1 (IGF-1) level. The arrows indicate pasireotide administration.

disease (1). They reported that lack of overt signs and symptoms therefore does not indicate the absence of the disease.

In pathological tissue examinations using the pituitary adenoma specimens removed 5 years previously, immunostaining revealed the presence of ACTH-positive cells in the tumor, but there were no GH-positive cells. In the World Health Organization's 2017 classification of pituitary tumors (WHO 2017), the expression of anterior pituitary hormones and transcription factors is confirmed by immunohistochemistry, and the anterior pituitary cells that may be the origin of adenomas are inferred and classified. The expression patterns of pituitary transcription factors such as PIT-1 or T-pit may reveal the origin and development of tumor cells. In our case, T-pit was expressed in the adenoma cells, but PIT-1 was negative.

Pasireotide is a multi-receptor-targeted, second-generation somatostatin analog. Pasireotide has been approved for the treatment of acromegaly, instead of first-generation somatostatin analogs, allowing patients to achieve a greater normalization of IGF-1 (8). Additionally, the difference from the first-generation somatostatin analog is that pasireotide has the highest affinity for SSTR5, the most abundantly expressed somatostatin receptor subtype in corticotrophs. A recent phase 3 trial showed that pasireotide is an effective treatment agent for some patients with Cushing's disease who have persistent or recurrent disease after initial surgery (9). It also suggests the superior efficacy of pasireotideLAR compared to a first-generation somatostatin analog, oc- 
treotide LAR, for the treatment of patients with acromegaly. Rajendran et al. reported the use of pasireotide in a rare and unusual case of pituitary macroadenoma co-secreting $\mathrm{GH}$, prolactin, and ACTH (10). In that case, the GH and IGF-1 levels improved significantly, but intermittent hypercortisolemia persisted. In patients with Cushing's disease, SSTR5 is the most abundant receptor expressed. In addition, tumors show low SSTR2 density due to hypercortisolism-induced SSTR2 down-regulation (11). Since pasireotide has a particularly strong affinity for SSTR5, it is considered that ACTH secretion was firmly suppressed in our case. In addition, it has been recently postulated that the expression of SSTR2 or SSTR5 may predict responsiveness to pasireotide in acromegaly $(12,13)$. Although it was negative for GH by immunostaining in pathological tissue examinations with the pituitary adenoma specimens removed 5 years previously, the immunostaining of SSTR2 and SSTR5 could therefore be useful when studying the therapeutic effect.

Our case is the first case in which pasireotide-LAR demonstrated effectiveness in controlling both Cushing's disease and acromegaly. Although our patient followed a favorable clinical course until the present time, we need to carefully observe the long-term course in the future.

In conclusion, pasireotide-LAR should therefore be considered when treating combined cases of Cushing's disease and acromegaly.

The authors state that they have no Conflict of Interest (COI).

\section{Acknowledgement}

We are sincerely grateful to all of the clinical staff from the department of endocrinology and metabolism (Kagawa University) who contributed to the present work. We would like to thank Dr. Okauchi, who is in charge of neurosurgery.

\section{References}

1. Roca E, Mattogno PP, Porcelli T, et al. Plurihormonal ACTH-GH pituitary adenoma: case report and systematic literature review. World Neurosurg 114: e158-e164, 2018.

2. Schneider HJ, Sievers C, Saller B, Wittchen HU, Stalla GK. High prevalence of biochemical acromegaly in primary care patients with elevated IGF-1 levels. Clin Endocrinol (Oxf) 69: 432-435,
2008.

3. Volante M, Brizzi MP, Faggiano A, et al. Somatostatin receptor type $2 \mathrm{~A}$ immunohistochemistry in neuroendocrine tumors: a proposal of scoring system correlated with somatostatin receptor scintigraphy. Mod Pathol 20: 1172-1182, 2007.

4. Khadgawat R, Suri A, Khandelwal D, Mukund A. Acromegaly with no pituitary adenoma and no evidence of ectopic source. Indian J Endocrinol Metab 15: 250-252, 2011.

5. Daud S, Hamrahian AH, Weil RJ, Hamaty M, Prayson RA, Olansky L. Acromegaly with negative pituitary MRI and no evidence of ectopic source: the role of transphenoidal pituitary exploration? Pituitary 14: 414-417, 2011.

6. Lonser RR, Kindzelski BA, Mehta GU, Jane JA, Oldfield EH. Acromegaly without imaging evidence of pituitary adenoma. J Clin Endocrinol Metab 95: 4192-4196, 2010.

7. Rasul FT, Jaunmuktane Z, Khan AA, Phadke R, Powell M. Plurihormonal pituitary adenoma with concomitant adrenocorticotropic hormone $(\mathrm{ACTH})$ and growth hormone $(\mathrm{GH})$ secretion: a report of two cases and review of the literature. Acta Neurochirurgica 156: 141-146, 2014.

8. Gadelha MR, Bronstein MD, Brue T, et al. Pasireotide versus continued treatment with octreotide or lanreotide in patients with inadequately controlled acromegaly (PAOLA): a randomised, phase 3 trial. Lancet Diabetes Endocrinol 2: 875-884, 2014.

9. Lacroix A, Gu F, Gallardo W, et al. Efficacy and safety of oncemonthly pasireotide in Cushing's disease: a 12 month clinical trial. Lancet Diabetes Endocrinol 6: 17-26, 2018.

10. Rajendran R, Naik S, Sandeman DD, Nasruddin AB. Pasireotide therapy in a rare and unusual case of plurihormonal pituitary macroadenoma. Endocrinol Diabetes Metab Case Reports 2013: 2013.

11. Cuevas-Ramos D, Fleseriu M. Somatostatin receptor ligands and resistance to treatment in pituitary adenomas. J Mol Endocrinol 52: 223-240, 2014.

12. Iacovazzo D, Carlsen E, Lugli F, et al. Factors predicting pasireotide responsiveness in somatotroph pituitary adenomas resistant to first-generation somatostatin analogues: an immunohistochemical study. Eur J Endocrinol 174: 241-250, 2016.

13. Muhammad A, Van Der Lely AJ, Delhanty PJD, et al. Efficacy and safety of switching to pasireotide in patients with acromegaly controlled with pegvisomant and first-generation somatostatin analogues (PAPE Study). J Clin Endocrinol Metab 103: 586-595, 2018.

The Internal Medicine is an Open Access journal distributed under the Creative Commons Attribution-NonCommercial-NoDerivatives 4.0 International License. To view the details of this license, please visit (https://creativecommons.org/licenses/ by-nc-nd/4.0/).

\section{(C) 2021 The Japanese Society of Internal Medicine} Intern Med 60: 1047-1053, 2021 